\title{
Wax-Impregnated Carbon Paste Electrode Modified with Mercuric Oxalate for the Simultaneous Determination of Heavy Metal Ions in Medicinal Plants and Ayurvedic Tablets
}

\author{
Ronald J. Mascarenhas, ${ }^{* 1}$ Ashis K. SatPatI, ${ }^{* 2}$ Shivaraj YellapPa, ${ }^{* 3}$ Bailure S. Sherigara, ${ }^{* 3 \dagger}$ \\ and Ajjikuttira K. BOPIAH*4 \\ *1 Department of Chemistry, St. Joseph's College, Lalbagh Road, Bangalore-560 027, Karnataka, India \\ *2 Analytical Chemistry Division, Bhabha Atomic Research Centre, Trombay, Mumbai, Maharashtra, India \\ *3 Department of Post-Graduate Studies and Research in Industrial Chemistry, Kuvempu University, \\ Jnana Sahyadri, Shankaraghatta-577 451, Shimoga, Karnataka, India \\ *4 Department of Botany, St. Joseph's College, Lalbagh Road, Bangalore-560 027, Karnataka, India
}

\begin{abstract}
A wax-impregnated carbon paste electrode with mercury oxalate as the bulk modifier is found to be suitable for the determination of heavy metal ions by differential pulse anodic stripping voltammetry. The contents of binder and modifier have been optimized, until they showed low background current and easy renewability. The bulk-modified electrode is applied for the simultaneous determination of $\mathrm{Zn}, \mathrm{Cd}, \mathrm{Pb}$ and $\mathrm{Cu}$ in medicinal plants and Ayurvedic tablets (Liv 52). The results obtained have been validated with HMDE and AAS and are found to be comparable.
\end{abstract}

(Received July 13, 2005; Accepted February 6, 2006)

\section{Introduction}

Anodic stripping voltammetry (ASV) is used most conveniently for the trace analysis of metals that are capable of forming amalgams after electro-reduction. ${ }^{1-3} \quad$ Differential pulse voltammetric methods have an advantage over linear scan stripping in that they discriminate effectively against charging current. ${ }^{4-6}$ Even though some other analytical methods, such as atomic absorption, inductive coupled plasma, X-ray fluorescence spectrometry and neutron activation analysis, ${ }^{7}$ have also been used for the trace analysis of metal ions, they involve high cost and maintenance and complicated procedures for analysis. Because of mercury's high toxicity, stability and volatility, use of metallic mercury to detect toxic heavy metal ions is a debatable issue. Mercury thin film electrodes are used due to their improved sensitivity; such films minimize the use of mercury compounds. ${ }^{8-14}$ However, they suffer from film stability, affecting the reproducibility of the results, ${ }^{15}$ and are not yet satisfactory. ${ }^{13,14}$ Thin films are electrochemically deposited onto the surface of the electrode or, either $\mathrm{Hg}^{+}$or $\mathrm{Hg}^{2+}$ can also be added to the solution and mercury film can be deposited simultaneously with the metals to be determined. ${ }^{8}$ Hence a solution containing mercury ions is used as a source of mercury.

The mercury film formation in solution can be replaced by $\mathrm{Hg}$ (II) diethyldithiocarbamate bulk-modified, ${ }^{16}$ composite electrodes containing $\mathrm{HgO}$ as a built-in mercury processor. ${ }^{17}$ Polymeric carbon composite electrodes with $\mathrm{HgCl}_{2}, \mathrm{HgO}$ and $\mathrm{Hg}_{2} \mathrm{Cl}_{2}$ in cyclohexanone containing a polymeric binder dispensed on the surface of the electrode ${ }^{18}$ have been reported.

$\dagger$ To whom correspondence should be addressed.

E-mail: bssherigara@rediffmail.com
CPE bulk-modified with mercury oxalate has been reported to be a suitable electrode ${ }^{19}$ for the detection of trace metal ions with lowered detection limits. CPE electrodes suffer substantially from the presence of oxygen entrapped in the paste brought in by carbon particles and are found to suffer from background currents ${ }^{20}$ and hence decreased sensitivity. The methods proposed to decrease background current are based on removing adsorbed electro-active species, mainly oxygen. Therefore, prior to preparing the paste, carbon powder is pretreated by heating at a high temperature, with subsequent impregnation of the pores by ceresin wax. ${ }^{21}$

The rapid diffusion of heavy metals as environmental contaminations has called for attention to their determination at trace and ultra trace levels. ${ }^{22,23}$ Such elements tend to concentrate in soil, biological and industrial samples. The determination of toxic trace metals is an important problem in environmental research, marine and aquatic chemistry, clinical and food chemistry.

The micronutrient $\mathrm{Zn}$ participates in biosynthesis of numerous proteins and activates hundreds of enzymes. ${ }^{24}$ Excess $\mathrm{Zn}$ may result in chronic metabolic disturbances and retardation of growth. ${ }^{25}$ If present in high concentration in the soil and or plant, it will interfere with the normal Fe metabolism in the plants, resulting in typical iron deficiency symptoms. ${ }^{26}$ An excess of copper will induce chlorosis and Fe deficiency. ${ }^{26} \mathrm{Cd}$ is nephrotoxic and can cause renal dysfunction with proteinuria. ${ }^{27}$ Normal levels of $\mathrm{Cd}$ in blood are below $5 \mu \mathrm{g}$ $\mathrm{L}^{-1} .^{28}$ Many studies both in human and animals have shown $\mathrm{Cd}$ to be potentially carcinogenic to human prostates. ${ }^{29,30}$ Lead concentration in blood provokes kidney and liver diseases and neurological damage in children in particular. ${ }^{31}$ A recent study ${ }^{32}$ conducted in Taiwan reported that the source of $\mathrm{Pb}$ contamination is not through drinking water nor through the food chain nor through exhaust gases from heavy traffic (on 
account of the use of unleaded gasoline) but through herbal medicine. Therefore the study concludes that special attention needs to be given to the possible lead content in certain special items such as herb medicine and nourishing diet items which are becoming popular.

Plants that are used in herbal medicines also get contaminated with these metal ions. Herbal medicines have been extensively used in India both in rural and in urban parts. They are becoming more popular even in western countries. Plant extracts have been used to prepare Ayurvedic and Sidha medicines. It has been estimated that as many as $75-90 \%$ of the world's rural people are dependent on herbal medicine for their primary health care. ${ }^{33}$ In rural India, the extracts of these plants are also used as such for the treatment of liver disorders and jaundice. With high awareness of the toxic effects of heavy metal ions on human, animal, plant and aquatic life, detection of these metal ions has become a global problem.

Our present study is aimed at avoiding metallic mercury. We report investigations on the electrochemical behavior of waximpregnated carbon paste electrode (WICPE) modified with mercury oxalate for the simultaneous determination of trace metal ions in medicinal plants. We have successfully applied such a technique for the determination of these metal ions in Ayurvedic tablets in which the extract of some of these plants are used. The plants chosen and their medicinal uses ${ }^{33-36}$ for the treatment of different diseases are: i) Phyllanthus niruri: jaundice, urinary disorders and chronic dysentery; ii) Eclipta alba: jaundice, bronchial asthma, anemia and disease of liver and spleen; iii) Becopa monnieri: anemia, epilepsy, leprosy, etc.; iv) Boerahavia: jaundice, diuretic, asthma and dropsy associated with chronic Brights disease; v) The tablet Liv 52 has been shown to improve the functional efficiency of the liver and regulates levels of enzymes and optimizes assimilation. It is found to be very effective in hepatitis $\mathrm{A}^{37}$ and acute viral hepatitis. ${ }^{38}$ It neutralizes all kind of toxins and poisons from food, water, air and medications.

We have validated this method through comparison with HMDE and AAS.

\section{Experimental}

\section{Apparatus}

Measurements were done using the Eco Chemie-make potetiostat/galvanostat AUTOLAB-100 and the analysis was made using GPES software. All the experiments were carried out at the Analytical Chemistry Division of Bhabha Atomic Research Centre, Trombay, Mumbai, India. Anodic stripping measurements were performed using a conventional onecompartment three-electrode system. Wax-impregnated carbon paste bulk-modified with mercuric oxalate was used as working electrode, a saturated calomel electrode was used as reference and a platinum rod was used as the auxiliary electrode. For studies using HMDE, a Metrohm-make VA stand 663 electrode assembly was used. Stirring was done using a teflon-coated bar in a magnetic stirrer at approximately $200 \mathrm{rpm}$.

\section{Chemicals and reagents}

The sodium acetate, mercuric nitrate, oxalic acid and potassium chloride used were of analytical grade from E-Merck. The graphite powder used was spectroscopic grade. All acids used were of E-Merck suprapure grade. Required standard solutions of $\mathrm{Cu}, \mathrm{Pb}, \mathrm{Cd}$ and $\mathrm{Zn}$ were prepared by appropriate dilution of stock solution with nano pure deionized water. To transfer all the standard solutions to the electrolyte, micropipettes with disposable tips were used. All pieces of glassware used were washed with 1:1 $\mathrm{HNO}_{3}$ acid and rinsed with doubly distilled deionized water. The supporting electrolyte was $0.1 \mathrm{M}$ sodium acetate solution.

\section{Preparation of mercuric oxalate}

One equivalent of a solution of mercuric nitrate was mixed with an equivalent of oxalic acid solution. The precipitate that formed was filtered, washed several times with doubly distilled deionized water and dried in an oven at $343 \mathrm{~K}$ for $1 \mathrm{~h}$. The purity of the sample was confirmed by XRF data, which showed peaks corresponding to $\mathrm{Hg}$ only.

\section{Preparation of the working electrode}

Wax-impregnated carbon powder was prepared by taking 9.5 $\mathrm{g}$ of spectroscopic grade carbon powder in a quartz tube, which was placed in a tube furnace. It was then heated to a high temperature to remove adsorbed oxygen. ${ }^{21}$ This powder was added to an appropriate quantity of ceresin wax dissolved in warm $n$-hexane, ${ }^{39}$ the mixture was placed in a water bath, stirred and heated till the $n$-hexane evaporated. For the preparation of the modified electrode, the modifier (mercuric oxalate) ranging from $6 \%$ to $18.37 \%$ (mass of the modifier to the total mass of the carbon paste) was prepared by weighing out an appropriate quantity of the modifier into an agate and grinding it thoroughly to get a fine powder. This was then mixed with waximpregnated carbon powder and ground. The required quantity of silicone oil was added as the binder ( $44 \%$ of the mass of modifier and carbon powder) and ground well to get homogeneous paste. The electrode consisted of a Teflon well, which was mounted at the end of a Teflon tube. The homogenized paste was filled into the Teflon well. A copper wire fixed to a graphite rod and inserted into the Teflon tube served to establish electrical contact with the external circuit.

\section{Sampling}

The plant samples were taken from the outskirts of Bangalore city of Karnataka state in India. About $1 \mathrm{~kg}$ of leaf samples from each of the medicinal plants were taken into precleaned polyethylene bags. The material was then washed using 1:10 $\mathrm{HCl}$ and rinsed with distilled and deionized water and sealed. The leaves were dried for $24 \mathrm{~h}$ at $333 \mathrm{~K}$. The samples were then ground and homogenized in the lab using a precleaned mortar and pestle. ${ }^{40}$ The ground samples were then packed into precleaned plastic bags and stored.

\section{Sample treatment}

An aliquot of $1 \mathrm{~g}$ of finely powdered leaf sample was subjected to acid digestion. Similarly, Ayurvedic tablets (Liv 52) were first cleaned in order to remove the outer coating, then dried and powdered using a mortar and pestle. One gram of this powder was weighed out into a clean conical flask and subjected to acid digestion.

\section{Procedure}

A modified electrode was placed in the stirred deaerated 0.1 $\mathrm{M} \mathrm{HCl}$ solution at a deposition potential of $-0.9 \mathrm{~V}$ for $180 \mathrm{~s}$ for the formation of metallic mercury on the surface, thereby making the electrode active. The electrode was then washed gently with distilled water and put into a deaerated $0.1 \mathrm{M} \mathrm{KCl}$ solution containing different metal ions to be analyzed. The deposition was carried out at $-0.9 \mathrm{~V}$ (SCE) for cadmium for 120 $\mathrm{s}$ in stirred solution. After $15 \mathrm{~s}$ quiescent period, the potential scan was started in differential pulse mode from -0.9 to $0 \mathrm{~V}$ (SCE). For the simultaneous determination of $\mathrm{Pb}, \mathrm{Cu}, \mathrm{Zn}$ and 
$\mathrm{Cd}$, an initial potential of $-1.30 \mathrm{~V}$ to an end potential of $+0.1 \mathrm{~V}$ was used. This deposition potential and the range of potential scan may vary on the condition and the metal ions to be analyzed. For the determination of heavy metal ions in medicinal plants, $\mathrm{Na}$ acetate buffer was used, keeping all other stripping parameters almost the same as above. The deposition time for the reduction of $\mathrm{Hg}(\mathrm{II})$ to $\mathrm{Hg}(0)$ was optimized to $180 \mathrm{~s}$ in $0.1 \mathrm{M} \mathrm{HCl}$ acid solution. The deposited $\mathrm{Hg}$ was removed mechanically by removing some paste and polishing the material on a piece of transparent paper; a fresh surface was exposed each time before conducting a new experiment. Linear scan voltammetric (LSV) studies using the modified electrode were carried out to see its electrochemical behavior in the blank supporting electrolyte solution i.e. only in sodium acetate buffer. The potential was scanned from $-1.30 \mathrm{~V}$ to $+0.1 \mathrm{~V}$ and a stable base line was obtained. Therefore, the modified electrode in the current study could be used for the determination of $\mathrm{Pb}, \mathrm{Cu}, \mathrm{Cd}$ and $\mathrm{Zn}$ successfully where the potential window was between $-1.30 \mathrm{~V}$ to $+0.1 \mathrm{~V}$.

\section{Results and Discussion}

Mercuric oxalate modifier was exposed to the solution interface, on electroreduction forms mercury droplets, which act as the active surfaces of the present analysis. The characteristic properties of the electrode are dependent on the carbon-powderto-binder ratio and also on the amount of surface mercury. The lower percentage of binder affected the peak heights as well as the mechanical stability. The binder composition was optimized to $42 \%$ of the total weight. The weight $\%$ of the modifier was also optimized. The content of mercuric oxalate in the modifier was varied from 6.0 to 18.37 weight $\%$. The resolutions of adjacent peaks were poor at lower percentages of the modifier. Mercuric oxalate of 18.37 weight $\%$ was found to be suitable for our study and this amount was kept constant throughout the experiments. It is observed that waximpregnated carbon paste electrode gave low background current and well-defined peaks. However, there was a shift in the peak potentials. For a mercury thin film electrode, ${ }^{41}$ this appearance of peak potentials has been shown to vary with factors such as thickness of film, rate of diffusion of oxidized species, thickness of surface diffusion layer and scan rate. As reported elsewhere, complexation ${ }^{42}$ also may produce a negative shift in the diagnostic parameter $E_{\mathrm{p}}$.

\section{EIS and SEM analysis}

The electrochemical impedance results suggest that charge transfer resistance values reduced with the increase in the modifier concentration of up to $18.37 \%$ (from $2.3 \times 10^{6} \Omega$ for $6 \%$ to $3.5 \times 10^{5} \Omega$ for $18.37 \%$ ). Above this concentration, no significant increase in charge transfer resistance has been observed. Smoothening of the electrochemically active surface has also been seen from the surface roughness parameter, which increases from 0.8 to 0.95 (close to unity) upon increase in the modifier concentrations. SEM analysis revealed a random distribution of the deposited mercury in the form of droplets, which is evident from the conducting and nonconducting regions on the surface. ${ }^{17}$ The particle size of mercury oxalate was found to be 2 to $3 \mu \mathrm{m}$ on an average and that of mercury droplets was found to be $0.8 \mu \mathrm{m}$.

\section{Stability of the electrode}

The bulk-modified carbon paste was found to be stable. Once the paste was prepared, it was left overnight for self-

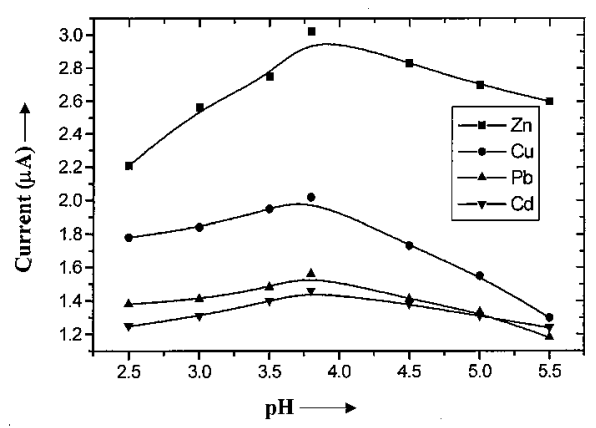

Fig. 1 Effect of $\mathrm{pH}$ on the stripping currents of $75 \mathrm{ppb}$ of each metal ion at WICPE: deposition potential, $-1.3 \mathrm{~V}$; deposition time, $120 \mathrm{~s}$; step potential, $5 \mathrm{mV}$; modulation amplitude, $25 \mathrm{mV}$; modulation time, $0.05 \mathrm{~s}$; interval time, $0.2 \mathrm{~s}$.

homogenization. The self-homogenized paste was found to be stable with improved reproducibility. The measurements that were carried out even after 38 days showed the stability of the paste and the excellent reproducibility.

LSV

The value of peak potential obtained by us for mercury oxidation is in agreement with what has been reported. ${ }^{43}$ The background currents happened to be very small within the current range employed for the study. There was a shift in hydrogen evolution potential towards the more negative direction at the modified electrode after activating it in $0.1 \mathrm{M}$ $\mathrm{HCl}$.

\section{Interference effect}

In trace analysis experiments, organic complexants provide one of the serious interference factors, as most of the organic compounds have the reducible or oxidizable moieties, which are electrochemically active at the mercury electrode and form the bonding of metal-ligand complexes. For this purpose, leaf samples were digested thoroughly by acid digestion to suppress the organic matrices and to separate the free metal ions. The presence of oxygen may interfere with such a system. So the solutions were purged with nitrogen gas and the solution was blanketed with a stream of nitrogen gas.

\section{Effect of $p H$}

At higher $\mathrm{pH}$, the peak height fell and the peak current for $\mathrm{Cu}$ reduced drastically. However with $\mathrm{Cu}$ and $\mathrm{Pb}$, increasing the acidity enhances the ASV peak size and peaks tend to be sharper, which leads to a greater sensitivity for the determination of $\mathrm{Cu}$ and $\mathrm{Pb}$. It has been postulated that $\mathrm{Cu}$ forms a series of compounds ${ }^{44}$ of general formula $\mathrm{Cu}_{n}(\mathrm{OH})_{2 n-2}\left(\mathrm{H}_{2} \mathrm{O}\right)_{4}$, where $n$ increases with $\mathrm{pH}$ and that there are seven different hydroxyl species in the lead system. ${ }^{45}$ At $\mathrm{pH}$ values lower than 3.8, the peak current of $\mathrm{Zn}$ decreased drastically and broadening of peaks took place at $\mathrm{pH}$ values higher than 4.5. Therefore, the $\mathrm{pH}$ was optimized at 3.8 for the study. The effect of $\mathrm{pH}$ on stripping currents of heavy metal ions has been shown in Fig. 1 keeping the deposition time at $120 \mathrm{~s}$ and deposition potential at $-1.30 \mathrm{~V}$.

\section{Effect of deposition time}

The influence of accumulation time on the peak current was studied in the range $60-200 \mathrm{~s}$ as depicted in Fig. 2 at pH 3.8 and at a deposition potential of $-1.30 \mathrm{~V}$. At higher accumulation time, decreases in peak current of $\mathrm{Zn}$ and $\mathrm{Cu}$ were 


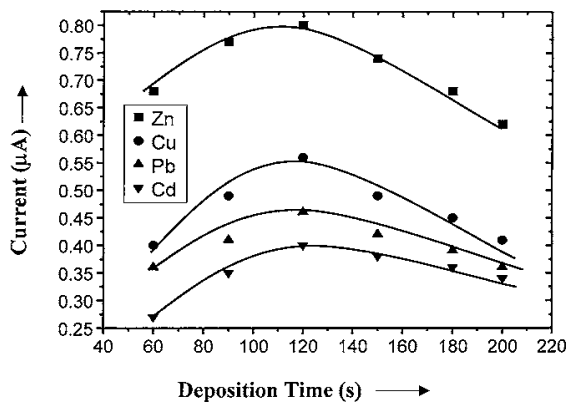

Fig. 2 Effect of deposition time on the stripping currents of $20 \mathrm{ppb}$ of each metal ion at WICPE, $\mathrm{pH}$ 3.8; all other instrumental parameters are the same as in Fig. 1.

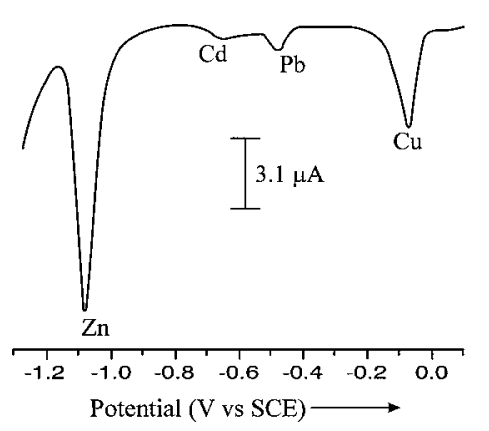

Fig. 3 Differential pulse anodic stripping voltammogram of $\mathrm{Zn}$ $\mathrm{Cd}, \mathrm{Pb}$ and $\mathrm{Cu}$ present in Phyllanthus niruri sample at WICPE electrode, $\mathrm{pH}$ 3.8; all other instrumental parameters are the same as in Fig. 1.

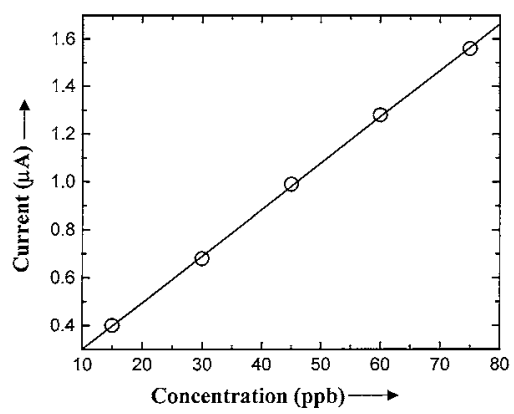

Fig. 4 Standard addition plot of $\mathrm{Cd}$ present in Phyllanthus niruri sample.

observed in the concentration range taken for the present analysis. This may be due to the formation of inter-metallic compounds of these metals. A deposition time lower than $100 \mathrm{~s}$ affected $\mathrm{Cd}$ determinations. A shorter deposition time affected $\mathrm{Cd}$ and $\mathrm{Cu}$ determinations to a relatively greater extent as compared to $\mathrm{Pb}$ and $\mathrm{Zn}$. Therefore, the accumulation time was optimized at $120 \mathrm{~s}$.

\section{Effect of deposition potential}

The variation of deposition potentials on the stripping currents of various metal ions was studied. Potentials more negative than $-1.40 \mathrm{~V}$ cause hydrogen evolution, which affected the peak currents. The mercury droplets were distorted by the evolved hydrogen, which leads to increased base currents, which in turn has direct consequences on the reproducibility. The potentials more positive than $-1.30 \mathrm{~V}$ affected the stripping peak of $\mathrm{Zn}$.
Table 1 Metal ion concentration $\left(\mathrm{mg} \mathrm{kg}^{-1}\right)$ in medicinal plant leaves and Ayurvedic tablets (Liv 52) using WICPE, HMDE and AAS

\begin{tabular}{|c|c|c|c|c|c|}
\hline Sample & Medicinal plant & $\mathrm{Cu}$ & $\mathrm{Pb}$ & $\mathrm{Cd}$ & $\mathrm{Zn}$ \\
\hline \multirow[t]{4}{*}{1} & Phyllanthus niruri & & & & \\
\hline & WICPE & 26.7 & 1.72 & 0.200 & 61.0 \\
\hline & HMDE & 26.3 & 1.70 & 0.195 & 60.0 \\
\hline & AAS & 28.1 & 1.75 & 0.193 & 64.8 \\
\hline \multirow[t]{4}{*}{2} & Eclipta alba & & & & \\
\hline & WICPE & 14.5 & 0.21 & 0.056 & 31.3 \\
\hline & HMDE & 14.1 & 0.22 & 0.060 & 33.2 \\
\hline & AAS & 12.2 & 0.25 & 0.055 & 30.7 \\
\hline \multirow[t]{4}{*}{3} & Becopa monnieri & & & & \\
\hline & WICPE & 12.0 & 0.70 & 0.130 & 38.3 \\
\hline & HMDE & 12.0 & 0.69 & 0.125 & 42.2 \\
\hline & AAS & 10.0 & 0.70 & 0.125 & 40.0 \\
\hline \multirow[t]{4}{*}{4} & Boerahavia & & & & \\
\hline & WICPE & 7.0 & 2.84 & 0.21 & 23.0 \\
\hline & HMDE & 7.1 & 2.84 & 0.18 & 22.2 \\
\hline & AAS & 6.8 & 2.80 & 0.20 & 20.4 \\
\hline \multirow[t]{4}{*}{5} & Liv 52 & & & & \\
\hline & WICPE & 33.6 & 0.17 & 0.059 & 40.0 \\
\hline & HMDE & 32.3 & 0.18 & 0.062 & 42.0 \\
\hline & AAS & 34.0 & 0.15 & 0.052 & 39.0 \\
\hline
\end{tabular}

Therefore, an optimum potential of $-1.30 \mathrm{~V}$ was selected as a suitable accumulation potential for the study, as this allows the relevant elements to be deposited.

Typical differential pulse anodic stripping voltammograms of $\mathrm{Zn}, \mathrm{Cd}, \mathrm{Pb}$ and $\mathrm{Cu}$ present in Phyllanthus niruri at modified WICPE electrode are depicted in Fig. 3.

All the elements in unknown samples were determined by standard addition methods. A peak current corresponding to each different concentration of the analytes was measured and the plot of peak current $v s$. concentration of the standard was obtained. The data points of all the samples were fitted well with the straight line fitting, with the correlation coefficient of $\sim 0.999$ in almost all the cases. As a representative case, the standard addition plot of $\mathrm{Cd}$ in Phyllanthus niruri sample is shown in Fig. 4. The peak current values $i_{\mathrm{p}}$ followed a straight line equation with the concentration of the standards $(C)$ with the correlation coefficient of 0.9998 . The slope of the standard addition plot signifies the sensitivity of the method; in this case it is $0.0194(\mu \mathrm{A} / \mathrm{ppb}$ of $\mathrm{Cd})$. Standard addition plots of $\mathrm{Zn}, \mathrm{Cd}$, $\mathrm{Pb}$ and $\mathrm{Cu}$ for Phyllanthus niruri sample can be represented in the following equation forms; $i_{\mathrm{p}}=1.422+0.0520 C$ for $\mathrm{Zn}(R=$ $0.993), i_{\mathrm{p}}=0.106+0.0194 C$ for Cd $(R=0.999), i_{\mathrm{p}}=0.196+$ $0.0221 C$ for $\mathrm{Pb}(R=0.999)$ and $i_{\mathrm{p}}=0.772+0.0280 C$ for $\mathrm{Cu}(R$ $=0.999)$. The $3 \sigma$ detection limit for $\mathrm{Cd}(\mathrm{II})$ is obtained to $3 \times$ $10^{-9} \mathrm{M}$ at a deposition time of $120 \mathrm{~s}$.

Table 1 shows the relevant data for the stripping peaks of the heavy metal ions in medicinal plants and Ayurvedic tablet Liv 52 in sodium acetate buffer at $\mathrm{pH}$ 3.8. The values have been validated with HMDE and AAS.

The values obtained are well within the maximum permissible limits ${ }^{46}$ for human consumption.

\section{Conclusion}

Wax-impregnated carbon paste electrode bulk-modified with mercuric oxalate provides good sensitivity low background currents and good stability. The reduced metallic mercury can 
be re-oxidized electrochemically also and hence there is no difficulty in handling reduced mercury. Since the salt is taken in the carbon matrix, there is no need to take mercury in solution. The mercury film (more precisely, the assemblage of small mercury droplets) is very sensitive and the slightest mechanical disturbance leads to coalescence of the remaining droplets. Since the metallic mercury is sorbed within the waximpregnated paste there was not much problem with the mechanical stability. The results and observations have revealed that bulk modified WICPE is also a possible alternative to HMDE. This portable, easily renewable and relatively inexpensive method with a minimum use of mercuric oxalate and a possibility of re-oxidizing reduced mercury has the potential to become a useful tool for trace analysis. Further work in this area is in progress in our laboratory to explore the possibilities of applying this technique to soil and water samples.

\section{Acknowledgements}

Ronald J. Mascarenhas is grateful to Dr. M. Sudersanan, Head, Analytical Chemistry Division, Bhabha Atomic Research Centre (BARC), Mumbai, India, and to Dr. Palrecha, Senior Scientist, Analytical Chemistry Division, BARC, Mumbai, India for their guidance, discussion and help.

\section{References}

1. J. Wang, "Stripping Analysis: Principles, Instrumentation and Applications", 1985, VCH, Florida.

2. W. Kemula, Rakowska, and Z. Kublik, J. Electroanal. Chem., 1959, 1, 205.

3. H. Z. Brainina, "Stripping Voltammetry in Chemical Analysis", 1974, Wiley, New York.

4. T. R. Copeland, J. H. Christie, R. A. Osteryoung, and R. K. Skogerboe, Anal. Chem., 1973, 45, 2171.

5. S. P. Kounaves, J. J. O'Dea, P. Chandrashekar, and R. A. Osteryoung, J. Anal. Chem., 1987, 59, 386.

6. J. G. Osteryoung and R. A. Osteryoung, Anal. Chem., 1985 , 57, 101A.

7. P. A. Waller and W. F. Pickering, Talanta, 1990, 37, 981

8. T. M. Florence, J. Electroanal. Chem., 1970, 27, 273.

9. W. Lund and M. Salberg, Anal. Chim. Acta, 1975, 76, 131.

10. M. Wojciechowski and J. Balcerzak, Anal. Chem., 1990, 62,1325 .

11. J. Wang and B. Tian, Anal. Chem., 1992, 64, 1706.

12. R. G. M. Carra, A. Sanchez-Misiego, and A. Zirino, Anal. Chem., 1995, 67, 4484.

13. H. P. Wu, Anal. Chem., 1994, 66, 3151.

14. H. P. Wu, Anal. Chem., 1996, 68, 1639.

15. W. Frenzel, Anal. Chim. Acta, 1993, 273, 123.

16. S. X. Guo and S. B. Khoo, Environmental Monitoring and Assessment, 1997, 44, 471.

17. K. Seo, S. Kim, and J. Park, Anal. Chem., 1998, 70, 2936.
18. T. Lee, K. Chung, and J. Park, Electroanalysis, 2002, 14 , 833.

19. S. B. Khoo and S. Guo, Electroanalysis, 2002, 14, 813.

20. K. Kalcher, J. M. Kauffmann, J. Wang, I. Svancara, K. Vytras, C. Neuhold, and Z. Yang, Electroanalysis, 1995, 71,5 .

21. J. Lindquist, Anal. Chem., 1973, 45, 1006.

22. C. Sarzanini and E. Mentaste, Ann. Chim. [Rome], 1991, $81,343$.

23. R. E. Clement, G. A. Eiceman, and C. J. Koester, Anal. Chem., 1995, 67, 221R.

24. J. Koper and R. Zamorski, Med. Vet., 1991, 47, 182.

25. N. Sayama, Y. Yoshida, K. Mori, H. Fukazawa, H. Hori, M. Nakazato, J. I. Tani, Y. Nakagawa, and S. Ito, Endocr. $J$. [Tokyo], 1998, 45, 767.

26. J. B. Jones, Jr., "Plant Nutrition Manual", 1998, CRC Press, LLC, Boca Raton, Florida.

27. C. A. Burtis and E. R. Ashwood, "Fundamentals of Clinical Chemistry", 1996, W. B. Saunders, PA.

28. I. Pais and J. B. Jones, "The Handbook of Trace Elements", 1997, St. Lucie Press, Boca Raton, Florida.

29. R. K. Ross, H. Shimizer, A. Paganini-Hill, G. Honda, and B. E. Henderson, J. National Cancer Institute, 1987, 78, 869.

30. V. Gulden, J. J. Kolh, and A. L. Berbeeck, Prostate, 1995, $27,250$.

31. A. J. Mc Michael, P. A. Baghurst, and N. R. Wigg, N. Engl. J. Med., 1988, 319, 468.

32. Y.-H. Hwang, Y. Ko, C.-D. Chiang, S.-P. Hsu, Y.-H. Lee, C.-H. Yu, C.-H. Chiou, J.-D. Wang, and H.-Y. Chuang, Environ. Res., 2004, 96, 274.

33. J. F. Caius, "The Medicinal and Poisonous Plants of India", 1986, Scientific Publishers, Jodhpur, India.

34. S. N. Yoganarasimhan, "Medicinal Plants of India", 1996, Vol. I, Interline Publishing Pvt. Ltd., Bangalore, India.

35. S. N. Yoganarasimhan and V. Chaladurai, "Medicinal Plants of India", 2000, Vol. II, Cyber Media, Bangalore, India.

36. S. G. Joshi, "Medicinal Plants", 2000, Oxford and IBH Publishing Co. Pvt. Ltd., New Delhi.

37. S. A. Kolhapure, Medicine Update, 2004, 12, 51.

38. R. Baijal, N. Patel, and S. A. Kolhapure, Medicine Update, 2004, 12, 41 .

39. J. S. Atuma and J. Lindquist, Analyst, 1973, 98, 886.

40. F. Jing, L. Hc, H. Tong, H. Liu, and L. Wang, Anal. Lett., 2002, 35, 2013.

41. E. A. Schonberger and W. F. Pickering, Talanta, 1980, 27 , 11.

42. P. L. Brezonik, P. A. Brauner, and W. Stumm, Water Res., 1976, 10,605 .

43. L. Luong and F. Vydra, J. Electroanal. Chem., 1974, 50, 379 .

44. D. Perrin, J. Chem. Soc., 1960, 3189.

45. B. Carrel and A. Olin, Acta Chem. Scand., 1960, 14, 1999.

46. S. G. Mishra and D. Mani, "Metallic Pollution", 1st ed., 1992, Ashish Publishing House, New Delhi. 